\title{
STUDIES ON MECHANICAL AND THERMAL PROPERTIES OF EPOXY/FLY ASH/NANOFILLER NANOCOMPOSITE: A REVIEW
}

\author{
Shilpi Tiwari \\ Department of Plastic Technology, School of Chemical Technology, \\ H B Technical University, Kanpur, India \\ Kavita Srivastava \\ Department of Chemistry, V S S D College, Kanpur, India \\ C L Gehlot \\ Department of Chemistry, School of Basic and Applied Sciences, \\ H B Technical University, Kanpur, India

\section{Deepak Srivastava} \\ Department of Plastic Technology, School of Chemical Technology, \\ H B Technical University, Kanpur, India
}

\begin{abstract}
A recent development in the field of eco-friendly, lightweight and highperformance nanocomposite and a broad range of their innovative applications attract enormous interest in the field of research. However, the search for lighter materials to replace legacy heavy materials in engineering structures especially in automobile and aerospace industries has made the study of tribological properties of epoxy resin based composites significant. Fly ash, from the thermal power plant, is an industrial by-product that can be utilized as filler in epoxy resin with different wt\% owing to its distinctive properties like low density, wide availability, good filler factor, good thermal resistance, and glassy nature instead of dumping into the large area of landfills and ash ponds. In this investigation broaden literature groundwork also covers the effect of nanoparticles on thermal, morphological and mechanical characteristics such as impact strength, tensile strength and flexural strength of fly ash/epoxy nanocomposites.
\end{abstract}

Keywords: Fly ash, nanofiller, epoxy resin, nanocomposites, mechanical properties.

Cite this Article: Shilpi Tiwari, Kavita Srivastava, C L Gehlot and Deepak Srivastava, Studies on Mechanical and Thermal Properties of Epoxy/Fly Ash/Nanofiller Nanocomposite: A Review. International Journal of Civil Engineering and Technology, 11(2), 2020, 120-139. https://iaeme.com/Home/issue/IJCIET?Volume=11\&Issue=2 


\section{HIGHLIGHTS}

- Summarized the utilization of industrial pollutant fly ash as filler into the different matrix.

- Summarized general methods of fabrication of epoxy/fly ash nanocomposites.

- Reviewed literature on the effect of fly ash and various nanofillers on thermal, mechanical properties such as Tensile strength, Impact strength, Compressive strength and Hardness of epoxy/fly ash nanocomposites.

\section{INTRODUCTION}

Fly ash is an industrial waste residue generated by the combustion of pulverized coal in the Thermal power plant. During the combustion of coal in the boiler, the volatile matter and carbon burn off while the impurities like shale, quartz, clays feldspar, become fuse and stay in suspension. These fuse lightweight particles are ejecting out of the boiler of the combustion chamber with flue gases. When flue gas accesses the low-temperature zone, the fused particles solidify rapidly to form spherical particles. Earlier to draining the flue gases, spherical particles of ash are arrested by electrostatic precipitators. These spherical particles are known as fly ash. And the resting particles which aggregate rest down at the bottom of the furnace are called bottom ash [1]. About $90 \%$ of the total thermal power generation in India is based on coal. At present scenario in India, there are 167 coals based thermal power plants where 400-550 MT coal is being used every year which discharges 190 MT ashes and out of this $70-80 \%$ is fine to fly ash. By the end of the year 2018, about 200 million tons of fly ash was produced by various thermal power plants in India. The production of fly ash expected to increase to 250-300 MT/year by 2019-20. Therefore the stock of fly ash is increasing every year [2-3]. Apart from a small quantity of fly ash is primarily utilized by the cement industry, while an abundant proportion goes to ash ponds and landfills which cause huge environmental problems. In 2012, six million metric tons fly ash was produced by the UK out of which only $50 \%$ was utilized by the construction sector, while 50\% proportion was gone to landfills. Fly ash also contains toxic metals and traces the concentration of heavy metals such as cadmium, chromium, cobalt, lead, manganese, mercury, molybdenum, and selenium. These heavy metals affect human health like permanent respiratory disorder on inhalation of the presence of toxic metals especially by persons living in the vicinity of disposal sites [4-5]. The toxicity of heavy metals also leached out to underground water. The presence of excess chromium (VI) in fly ash could lead to damage circulatory systems and causes carcinogenic changes due to mutagenic properties associated with its oxidizing activity. Here it becomes obvious to reduce the environmental concern, greenhouse emissions, and disposal issues. So the utilization of fly ash becomes necessary. Fly ash has low-cost effectiveness as compared to other inorganic fillers [6-7]. It is used as the primary reinforcement material in the composite. The article presents the utilization of industrial waste like FA as reinforcement for matrix in making lightweight, high strength composites. The main objective for the utilization of fly ash in polymer composites has been its surface polarity due to the presence of silanol, aluminol and other types of -OH groups attached to the metal/non-metal atoms of the constituents of fly ash [8]. Overall, the polymer matrices are chosen on account of adhesive strength, fatigue resistance, heat resistance, chemical and moisture resistance, etc. Therefore for strengthening applications, a structural resin-like thermosetting matrix such as epoxy-based on DGEBA [diglycidyl ether Bisphenol A], needs to be used. Epoxy resin can be widely used to develop composite material due to its superior properties like excellent adhesion to filler, higher thermal stability, easy processing ability, good chemical resistance and low density [9]. However, properties associated with epoxy like undesirable brittleness due to a high degree of cross-linking structure, delamination, low impact strength, and poor cracking resistance made the limited application of epoxy. From a notable time, researchers have been investigating to 
get rid of these drawbacks of epoxy and observed that the advancement in mechanical and physical properties such as toughness, rigidness, and strengthening can be acquired from the modification of matrix or by reinforcement of various fillers. The filler/epoxy nanocomposites are extensively used in engineering, anti-corrosive coatings, electronic materials, and aerospace industries [10]. So the question arises, "What are nanocomposites"? In nanotechnology, the nanocomposites are classified as advanced heterogeneous solid material having two or more phase where at least one phase has a dimension in nanometer $[1 \mathrm{~nm}$ to $100 \mathrm{~nm}]$, which are regarded as promising alternatives to overcome the drawback of the polymer matrix, micro, and conventional composites. The development of nanotechnology has induced material restructure which change the properties of the material. It has reported that epoxy resin, reinforced with nanofiller has superior mechanical strength and thermal stability. The nanofillers help to enhance the quality of the product when introduced into the polymer matrix even at very low content (less than 10\%). The improvement of mechanical properties and thermal stability is credited to intensely higher surface area and uniform dispersion of nanoparticles with low volume fraction [11]. The nanofillers are incorporated in the form of particles, nanotubes, and whiskers (metallic or nonmetallic single crystal). The performance and characteristics of composites expect the size of reinforcement material, shape, concentration, adaptability with the matrix, the way the filler distributed in matrix, and volume fraction. The interface is also an imperative property of nanocomposite. The nanofillers are used as the secondary reinforcement material in the epoxy/fly ash nanocomposite.

In the literature survey, during the fabrication of epoxy/fly ash nanocomposite, two main challenges i.e. homogeneous dispersion of nanofiller and interfacial nanofiller polymer interaction are encountered. Because nanofiller attributing to a higher ratio of surface to volume, nanoparticles arranged adjacently and form aggregate which restricted homogeneous dispersion of nanoparticles in the polymer matrix [12]. Due to injurious effect of the inorganic nanofillers, there is the strong prospect of agglomeration. Debonding and agglomeration of particle are major problem encountered in the fabrication of polymeric nanocomposites; induce the most problems in nanocomposite research. The results are reported that stirring methods had an indicative effect on dispersion quality because voids exist between nanofiller and matrix reduces the mechanical properties of polymer nanocomposite. Numerous physical stirring methods such as mechanical stirring, high shear mixing, solvent mixing, and ultrasonic bath stirring have been explored to attain a homogeneous dispersion of nanofiller in the matrix. Ultrasonic vibrations make effectiveness in improving the uniform dispersion of nanofillers [13]. Therefore this review article discusses the polymer nanocomposites reinforced with fly ash, epoxy and nanofiller due to their interesting as well as their unique applications. The knowledge of the immense value of nanocomposites will enable the manufacturer to recognize that polymer nanocomposites will herald a new era in material advancement just as polymer composites transformed the face of industry many years ago.

\section{RAW MATERIALS FOR THE FABRICATION OF EPOXY/FLY ASH NANOCOMPOSITE}

From the literature review it is reported that the development of epoxy/fly ash/nanocomposite is based on epoxy resin, fly ash from the thermal power plant and various types of nanofillers as reinforcing phase.

\section{CHEMICAL AND PHYSICAL CHARACTERISTICS OF FLY ASH}

Fly ash is heterogeneous material having various elements such as $\mathrm{C}, \mathrm{K}, \mathrm{Al}, \mathrm{Si}$, Ca present in form of metal oxides like $\mathrm{SiO}_{2}(60-70 \%), \mathrm{Al}_{2} \mathrm{O}_{3}(20-25) \%$ and $\mathrm{Fe}_{2} \mathrm{O}_{3}(2-3) \%$. These oxides 
lead to positive effects when used as reinforcing the material in the polymer matrix [14]. The presence of $\mathrm{Al}_{2} \mathrm{O}_{3}$ is due to the existence of clay in fly ash. Besides of these metal oxides, some other chemicals like alkalies, $\mathrm{MgO}$, carbon, and $\mathrm{SO}_{3}$ also present in the fly ash. Ibraheem S.et al. [15] studied that fly ash has metal oxides that show good effects when embedded in the polymer matrix. SIMS technique has been performed to identify the interfacial distribution of fly ash with $10 \mathrm{wt} \%$ and $15 \mathrm{wt} \%$.

The quality of fly ash is based on several factors such as type of coal, fineness of coal particles, and content of ash present in coal. The particle size of fly ash varies from 1 to $150 \mu \mathrm{m}$. The color of fly ash differ from gray to black depends on the content of carbon present in the ash. Darker the gray to black color of fly ash greater will be chances of the content of suspended unburned carbon in the ash while the brown color typically correlates with the presence of higher content of iron. The light and tan colors of fly ash are attributed to the presence of higher content of lime present in the ash. [16]. It is revealed that fly ash is adsorbent for the elimination of numerous by-products. The unburned carbon present in fly ash is involved in adsorption capacity [17]. The $\mathrm{pH}$ of fly ash alters from 4.5 to 12 depending upon the particle size as well as the consequent concentration of trace metals [18]. Fly ash consists of both the glassy and crystalline phase; the 60 to $90 \%$ of the total mass of fly ash is the glassy phase while remaining is crystalline. The glassy hollow spheres and crystalline phases are dependent on one another and alter in their proportions, which lead to fly ash a complex material to classify and characterize. The glassy phase of fly ash includes solid, hollow spheres called Cenospheres, extent in size from 0.5 to $300 \mu \mathrm{m}$, which help in proper binding to fill the intermolecular gap between polymer matrix material layers, which help in developing high value-added material. They furnish the benefit of a decrease in weight attributing to their low densities [19]. Nath S. et al. [20] studied that fly ash is industrial pollutant consists of cenosphere, hollow spherical particles which might be developed highperformance composite material with incorporation into the bio-reinforced composite material. Generally, the specific gravity of fly ash differs around $1.7-3.1 \mathrm{~g} / \mathrm{cm}^{3}$. The variation in specific gravity arises due to chemical composition and shapes of particles. The lower value of specific gravity depends upon several hollow cenospheres. The physical, mineralogical and chemical characteristics of fly ash rely upon the composition and variety of the coal carried out for combustion in the boiler and method of combustion.

\section{CLASSIFICATION OF FLY ASH}

Based on the source of coal, their chemistry and the amount of content silica, iron, calcium and alumina, ASTM C618 defines fly ash into two classes: Class C and Class F fly ash [21].

\subsection{Class F Fly ash}

This class of fly ash is generated by the combustion of harder and older anthracite and bituminous coal. The amount of lime $(\mathrm{CaO})$ content is less than $7 \%$ in class $\mathrm{F}$ fly ash. It contains a lower concentration of $\mathrm{Fe}_{2} \mathrm{O}_{3}$ and the higher concentration of silica about $60 \%$. This is highly pozzolanic so this class of fly ash is utilized in producing cementitious compounds. It has been revealed that as compared to other countries, the low lime Class F fly ash of India has more crystalline nature. In Indian fly ash, the ratio of network formers $\left(\mathrm{SiO}_{2}\right.$ $\left.+\mathrm{Fe}_{2} \mathrm{O}_{3}+\mathrm{Al}_{2} \mathrm{O}_{3}\right)$ to network modifiers $\left(\mathrm{Na}_{2} \mathrm{O}+\mathrm{K}_{2} \mathrm{O}+\mathrm{CaO}+\mathrm{MgO}\right)$ is too high and unbalanced to form high proportions of glass because class $\mathrm{F}$ type includes higher fusion temperature for the material. Class F fly ash contains a higher amount of alkali and sulfate. 


\subsection{Class C Fly ash}

This class of fly ash is generated by the combustion of younger sub-bituminous coal. Class $\mathrm{C}$ FA content more than $20 \%$ lime $(\mathrm{CaO})$. Generally, the amount of alkali and sulfate contents is less in Class $\mathrm{C}$ fly ash. Both types of fly ash consist of 25 to $28 \%$ of $\mathrm{Al}_{2} \mathrm{O}_{3}$. Table. 1 describes the chemical composition of fly ash[21].

Table 1 Chemical composition of fly ash

\begin{tabular}{|c|c|c|}
\hline Constituents & Class F Fly ash (Vol \%) & Class C Fly ash (Vol \%) \\
\hline $\mathrm{Fe}_{2} \mathrm{O}_{3}$ & 8.44 & 6.86 \\
\hline $\mathrm{Al}_{2} \mathrm{O}_{3}$ & 26.56 & 17.8 \\
\hline $\mathrm{SiO}_{2}$ & 55.85 & 42.46 \\
\hline $\mathrm{MgO}$ & 2.4 & 5.4 \\
\hline $\mathrm{CaO}$ & 6.59 & 22.25 \\
\hline \multicolumn{2}{|c}{} \\
\hline
\end{tabular}

\section{TRENDS OF FLY ASH PRODUCTION, UTILIZATION, AND PROBLEMS ENCOUNTERED IN DISPOSAL OF FLY ASH}

Central Electrical Authority of India (CEA) has been reporting the data of generation and utilization of fly ash from all thermal power plants since 1996. CEA has reported that during the year 2010-11, 2011-12, 2012-13, 2013-14, 2014-15, 2015-16, 2016-17 and 2017-18 the production of fly ash was 131.09, 145.42, 163.56, 172.87, 184.15, 176.74, 169.25 and 196.44 million tons whereas the utilization was $73.13,85.05,100.37,99.62,102.54,107.77,107.10$ and 131.87 million tons.

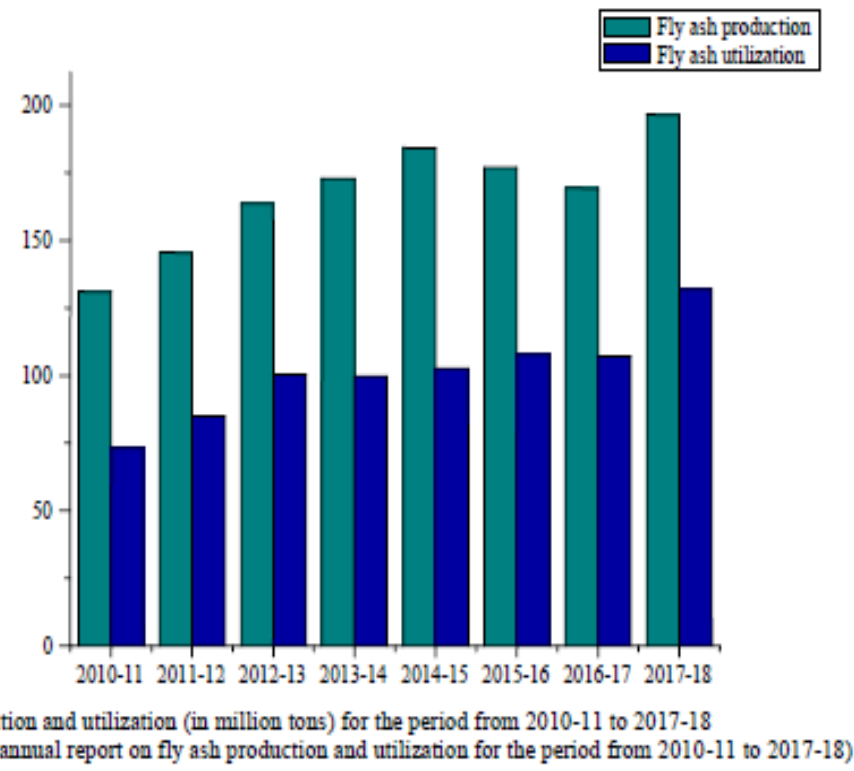

The enhancement in the production of fly ash might be due to the establishment of new thermal power plants [22]. During notable decades, there has been a gradual increment in the production of coal ash generated by thermal power plants in the world due to the increasing demand for energy. Therefore the stock of fly ash is increasing tremendously every year. Countries like India and China are exhibiting a rapidly increasing demand for coal. So long the requirement for energy expands more; the generation of fly ash is unavoidable. Researchers have studied compiled data of generation and utilization of fly ash across the world. In the United States, about $37 \%$ of total power generation is based on coal resulting in the production of 131 million tons of fly ash every year. The current worldwide scenario production of fly ash is more than 750 million tons. In 1989, the production of fly ash was 
about 560 million tons, out of which only 92 million tons of this (about $16 \%$ of total) was utilized by cement industries. However, the utilization of fly ash is very less still now. In 1989, Germany utilized the largest amount of fly ash about $47 \%$ while South Africa utilized the lowest amount of fly ash only $0.8 \%$ whereas the amount of utilization of fly ash was in Germany (17.9 million tons) followed by China (16.2 million tons) and USA (16.0 million tons). The worldwide scenario of the utilization of fly ash varies from $3 \%$ to 56\%. [20]. Less utilization of fly ash always makes a problem for disposal off. On 14 September 1999, the Ministry of Environment and Forests (MoEF) announced a regulation specifying prescriptive levels for gradual utilization for fly ash. As per regulation, it is compulsory for new thermal power plants to prescribed $100 \%$ utilization of fly ash within nine years of commencing operation whereas for old thermal power plants it is mandatory to achieve a goal of $100 \%$ fly ash utilization within 15 years from the date of the issue of the regulation of governance [2324].

However, various authors have studied the possible utilization of fly ash in innovative applications. Fly ash has been widely used as reinforcement material in the matrix such as epoxy resin due to its superior properties. Generally, the metallic particles are costly so the spherical particles of fly ash could assist the objective of reinforcement in epoxy matrix [25]. For the matrix mechanical strength compatibility with that of the incorporating material is necessary so epoxy resin is used as matrix for fly ash and nanofillers.

\section{CHARACTERISTICS OF EPOXY RESIN}

In 1936, Dr. Castan of Switzerland and Dr. Greenlee of the USA discovered epoxy resin. The matrix of the composite can be either composed of thermosetting or thermoplastic polymer. Thermoplastics have to mold at elevated temperature, as compared to thermosetting. Thermosetting has a cross-linking, three-dimensional network and highly strong structure. So the main attention is based on the thermosetting polymer such as epoxy resin. The epoxy resin is synthesized by the condensation reaction of epichlorohydrin with bisphenol. In epoxy resins, $\mathrm{ECHOCH}_{2}$ is a reactive group. Epoxy resin contains more than one epoxide group, oxirane or a glycidyl group. Based on the oxirane ring, the epoxy resins are classified into many categories. The epoxy system contains two parts, one part is resin and the second is hardener (curing agent) [26]. The glycidyl group of epoxy resin reacts with the reactive hydrogen of the curing agents such as aromatic amines, aliphatic amines, polyamides, phenols, and thiols. On the mixing of resin and hardener a chemical reaction proceeds which cures the material. Generally, amines are used as curing agents because amines contain reactive hydrogen, attached with nitrogen which opens the epoxy ring to form a covalent bond. On curing, epoxies have lower shrinkage. The temperature of the curing of epoxy resin is determined by the chemical composition of hardeners. The temperature range varies from 5 to $150^{\circ} \mathrm{C}$. As compared to low temperature cured epoxy system, high temperature cured epoxy system show higher glass transition temperature, tensile strength, and stiffness [27]. Many conventional materials are replaced by epoxy resin due to its superior properties. The enhancement in mechanical and physical properties can be obtained from the incorporation of various fillers [28-29]. 


\section{FABRICATION OF EPOXY/FLY ASH COMPOSITES}

For the preparation of epoxy/fly ash composites, the following techniques have been reported.

\subsection{Hand Lay-up Technique}

The Hand lay-up technique is the uncomplicated method of processing of composite. This technique is economically favorable. This technique is the oldest, simple and prevalent method for the production both of small and large fiber incorporated products.

It includes simple processing steps. Firstly, a lubricant is sprayed uniformly on the surface of the mold to prevent the sticking of polymer into the mold surface. To attain the excellent finishing of the surface of composite, the thin sheets are kept at the top of the mold. The strand mats are cut as per the block size of the mold and placed at the surface of the mold. Later the dough of thermosetting polymer with a convenient ratio of specified curing agent poured into the mold cavity. The mixture is uniformly spread with the help of a brush. After curing the mold is opened and the specimen of the composite is cut out from the sample sheet for different processed. Further, the second layer of the mat is kept on the surface of the polymer and a roller is lifted with moderate pressure to dismiss the air bubbles along with the presence of extra polymer. Some lubricant is drizzled on the inner surface of the mold further placed on stacked layers and pressure is adapted [30]. Purohit R. et al. [31] prepared fiber glass-epoxy-fly ash composites by using a hand lay-up technique with the addition of fly ash and glass fiber into epoxy resin. The fly ash was reinforced in epoxy resin with different wt $\%$ differ from 4-10 wt\% in steps of $2 \mathrm{wt} \%$. The main objective of this study was to observe the effect of fillers on the properties of composite such as micro structural properties and mechanical properties such as tensile strength, impact strength, and flexural strength.

\subsection{Stir Casting Method}

In the stir casting method, the dispersion of the dispersed phase into the molten matrix is performed by mechanical stirrer. Usually, in stir casting graphite stirrer is carried out due to tending to bear higher temperatures as compared to matrix. The stir casting method is convenient for the fabrication of the composites incorporated with $30 \%$ of reinforced material.

\subsection{Compo Casting}

The Campo casting process is based on the liquid state in which particles are reinforced to solidifying melt although being actively moved. It has been observed that primary solid particles previously create in the semisolid slurry can mechanically capture the incorporating particles, resulting in improved dispersion of particles in the matrix [32].

\subsection{In-Situ Deposition Technique}

In situ deposition technique, the addition of the reinforcing phase into polymer matrix carried out by disciplined metallurgical reactions so this process needs to screen carefully. Frequently one of the reacting elements is matrix while another may be fine powders. This type of reinforcement has attractive characteristics. It is highly systematic with a matrix and has fine particle size and homogeneous dispersion [33].

In the literature survey, the various nanofiller have been used as secondary reinforcing material to improve the mechanical and thermal properties of epoxy/fly ash composite has been described. 


\section{CHARACTERISTICS OF NANOFILLERS}

Nanofillers are those additives which enhance the properties of the material. Due to having a higher surface area, the nanoparticles show a tendency to form aggregates, resulting in micron-sized filler clusters which create a problem in the homogeneous dispersion of nanofillers in the polymer matrix [34-35]. The interfacial interaction between nanofiller and matrix material plays an important role. Certainly, the overall material properties adapt by the diversity in the macromolecular state region around the nanoparticles due to the high surface area of nanoparticles [36]. A well-dispersed system generally yields the most desirable properties. The dispersion of nanoparticles was characterized by the nano and micro scale. Carbon nanotubes and Graphenes draw enormous interest due to their unique structure and excellent properties. Various authors have developed the polymer nanocomposites based on various polymer matrixes with the nanofillers such as calcium carbonate, aluminum oxide, graphene, silica, carbon nanotubes and nanofibers [37].

\subsection{Classifications of Nanofillers}

Generally, nanofillers can be classified according to their number of dimensions 1D, 2D or 3D in nanocomposites, shape, and morphology [38]. The nanofillers are usually incorporated in the form of particles, nanotubes, fibers, and whiskers. The three types of nanofiller are given the following.

The first type of nanofiller is described by one dimension in the nanometer scale like needle-shaped material, laminas and/or shells. In this category, the filler consists of sheets of 1 to a few nm thicknesses and hundreds to thousands nanometer long. For example: nanoclay, nanosheets, nanoplatelets, and nanorods, etc.

The second type is characterized by one large and two-dimension in nanometer range forming elongated structure. In this group nanofiber, nanotubes or whiskers are studied. The nanotubes are generally classified into three main categories (1) SWNT (single-walled nanotubes) (2) DWNT (double-walled nanotubes) (3) MWNT (multiwalled nanotubes).

The third type of reinforcement consists of all three dimensions in the nanometre range. In this group, spherical silica, metal particles, semiconductor nanoclusters, and nanogranules are studied. Metal-based nanomaterials are those nanomaterials which can be obtained from the metals including quantum dots, nanogold, nanosilver and metal oxides, such as aluminum oxide, titanium oxide. Nanofillers are reinforced into the matrix at very low content from $1 \%$ to $10 \%$ (in weight).

Nanofillers are also reinforced in inclusion to other fillers like fly ash, sawdust, and additives, and ultimately incorporated with some fibers such as carbon, E-glass, etc. The various nanofillers are described as following.

\subsection{Nanoclay}

The organoclay nanoparticles of layered silica are known as nanoclay. The classification of nanoclay is based on the morphology of particles, crystalline structure, and chemical composition. Montmorillonite is most commonly nanoclay which is reinforced in polymer nanocomposite. And many material applications have revealed an enhancement in properties. Phyllosilicates consist of a shell-shaped structure with thickness in the nanometer range and their crystal lattice is made up of 2-D layers. The natural availability of clay and high form factor plays an important role in developing nanoclay based nanocomposites which create enhancement in physical performances. Nanoclay has a tendency of hydrophilic nature which creates difficulties in homogeneous dispersion within polymer matrixes [39]. Further, the better dispersion of a large amount of nanoclay within polymer matrixes can be acquired with 
hydrophobic surfactants by the exchange of metal ions with alkylammonium ions. The enhancement in chemical compatibility (interaction of nanoclay with matrix, resulting in good dispersion) may be attributed to the alkylammonium ions constituting the surface functionalities on nanoclays. Recently the related clays like kaolinite, hectrite and saponite have also reinforced in polymer nanocomposite

\subsection{Carbon Nanotubes}

Carbon nanotubes (CNT) were discovered in 1991 and gave an interesting approach to the modification of nanocomposites. The main aim of incorporation of CNT is based on the achievement of maximum dispersion into the polymer matrix. CNT is thin, carbon-containing long tubes including unique size and shape show superior mechanical and physical properties. CNT is a special type of fullerene thus the walls of CNT consists of hexagonal graphite structure. Generally, the three types of CNT are examined i.e. single-walled CNT (SWCNT), Double-wall carbon nanotubes (DWCNT) and multi-walled CNT (MWCNT). SWCNT exhibits a hollow structure procured by covalent bonding of carbon atom. The diameter of a SWCNT exists in the range of 0.6-2 nm, the diameter of DWCNT lies between 2 and $4 \mathrm{~nm}$, while the inner diameter of MWCNT in the 1.5-15 nm and the outer diameter of $2.5-50 \mathrm{~nm}$ [40-41]. In a vacuum, MWCNTs are thermally reliable up to $2800^{\circ} \mathrm{C}$. CNT exhibits superior electrical conduction similar to copper. CNT possesses 1/6 of the density of steel and shows 100 times better tensile strength than steel [42]. CNT also has excellent thermal stability than the purest diamond. The heat conductivity of CNT is $3000 \mathrm{~W} \cdot \mathrm{m}^{-1} \mathrm{~K}^{-1}$, electric conductivity of

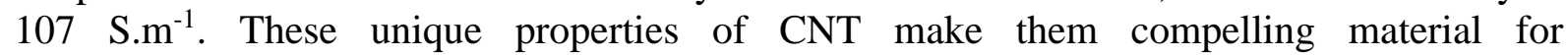
nanotechnology [43]. The CNT has wide applications in electronics, thermal and structural industry.

\subsection{Metallic Nanoparticles}

Since 1990, the metallic nanoparticles are in existence in the research field. The particle size of nanoparticles gravely relies upon the production approach of nanoparticles. Metallic nanoparticles correlate to spherical crystal shape of metals such as $\mathrm{Ag}, \mathrm{Au}$, and $\mathrm{Fe}$. The main objective of the reinforcement of this type of nanoparticle into the polymer matrix is based on the enhancement of the electrical conductivity of composites. The examples of Metallic nanoparticles are nanogold, nano zinc, nanosilver, nanodiamond, and quantum dots. These nanoparticles show catalytic property which creates antibacterial effects at the surface. Metallic nanoparticles consist of the dimension of particles in the range of 20 to $300 \mathrm{~nm}$ with surface areas of $20-500 \mathrm{~m}^{2} \mathrm{~g}^{-1}$. In comparison to their bulk counterparts, metallic nanoparticles possess different physical and chemical characteristics to have an enormous attraction to industrial applications. The property of high surface area to volume ratio makes metallic nanoparticles unique.

\subsection{Metal Nano Oxides}

The objective with nano-oxides is to obtain a maximized exfoliation and full dispersion into the matrix. The main aim of reinforcement of nano-oxide is to achieve homogeneous distribution and maximum exfoliation into the polymer matrix. Metal nano oxides are also used in commercial applications. In general, the examples of metal oxides are $\mathrm{ZnO}, \mathrm{CuO}$, $\mathrm{SiO}_{2}, \mathrm{TiO}_{2}, \mathrm{Fe}_{2} \mathrm{O}_{3}$, and $\mathrm{Al}_{2} \mathrm{O}_{3}$. 


\section{GENERAL METHODS OF FABRICATION OF EPOXY/FLY ASH NANOCOMPOSITES}

The surface modification for every type of nanofillers is achievable. The reinforcement of various types of nanofillers in any type of matrix has to need pre-treatment to enhance the interaction between matrix and nanofiller [44]. Based on various parameters the fabrication methods of polymer-based nanocomposites are classified. The process which occurs at the surface of material resulting in different physical and chemical behavior from one originally exhibit on the surface of the material is known as a surface modification. The different techniques such as the sol-gel process, in-situ polymerization, and solution mixing process, melt mixing process and in-situ intercalative polymerization were used for the fabrication of nanocomposites. The following techniques have been reported to modify the nanofillers and reinforced within the polymer to form a nanocomposite.

\subsection{In-Situ Polymerization}

In- situ word is derived from a Latin phrase that translates literally to "on-site" or "in position. In this method, nanoparticles are dispersed in monomer as well as in monomer solution. Further, this homogeneous mixture was initiated either by radiation or heat, relevant initiator or catalyst [45-46]. The main approach of In-situ-polymerization must be the desirable dispersion of nanofiller in the monomer. However, the difficulty arises due to the control of intragallery polymerization that makes limited applications.

\subsection{Melt-Intercalation Method}

This method is employed for polymer nanocomposite which consists of layered silicates such as montmorillonite and silica. In this method, nanocomposite fabricated with a uniform dispersion of plate-like inorganic nanofillers intercalated to exfoliation of layered silicate. Melt Intercalation methods are environmentally well dispose of but not compatible with industrial polymer processes [47].

\subsection{Sol-Gel Method}

This method is a tangled combination of in situ polymerization process and in situ formation of nanofiller as reinforcing phase.

\subsection{Intercalation Method}

The approach of this method is based on the reducement of fillers into nano dimensions. In this method, the exfoliation of layered silicates acts as inorganic filler exhibits by intercalating an organic compound into the interlayer space of silicate, resulting in a uniform and homogeneous dispersion of plate-like nanofillers [48].

\subsection{Template Method}

This method is performed to form particular shapes such as layered, hexagonal shape to nanocomposite materials. The formation of layers exhibits due to the presence of soluble polymer as a template. Mesoporous materials are widely synthesized by the template method but still lacking development of layered silicates. [49].

\subsection{Direct Mixing of Matrix and Nanoparticles}

In the direction polymerization method, the reinforcement between nanoparticles as the reinforcing phase and in polymerization takes place simultaneously. A catalyst or radical initiator starts the polymerization. The approach of direct mixing is based on the disruption of the agglomeration of fillers during the process of mixing [50]. Generally, the mixing of 
polymer and nanofiller followed in two ways. The first way is based on the mixing of polymer and nanofiller, in the absence of solvent whereas the second, the mixing of nanofiller and polymer matrix as in a solution is.

The above attempts were made to the uniform dispersion of nanofillers by using different methods for the fabrication of the surface of nanofillers. But the production of nanocomposite on an industrial scale, by these fabrication techniques, not suitable because these techniques required complicated chemical reactions. So the Direct melt-compounding method, a conventional method was developed because in this method the surface modification of nanofillers is not required.

Although, the prosperous applications of above various techniques for fabrication of polymer nanocomposites have been reported but the report on several factors is still deficient like the approach of convenient and lower cost process-based method for fabrication of high content nanofiller reinforced polymer nanocomposite to provide optimum property combinations.

\section{METHOD FOR DISPERSION OF FLY ASH AND NANOFILLERS IN MATRIX}

During the fabrication of epoxy/fly ash nanocomposite, two main greatest challenges endure i.e. homogeneous dispersion of nanofiller and interfacial nanofiller polymer interaction. Therefore, all the properties of nanocomposite are affected by better dispersibility of nanofiller, which provides maximum surface area for neighboring polymeric chains. Owing to an extremely higher ratio of surface to volume of nanofiller, the nanoparticles arrange adjacently and form micron-sized filler clusters aggregate which restricted homogeneous dispersion of nanoparticles in a polymer matrix. That attracts researchers to develop a preferred way of homogeneous dispersion and de-agglomeration of nanofillers [34-35]. This agglomeration of nanoparticle takes place due to a difference in the density of reinforced material and polymer matrix. This arises as an absence of needed force to breakdown it. By stirring at higher speed, the shearing force is enforced on polymer matrix resulting in transition for the reinforced phase to motion inside over the vortex produced by stirring. The higher speed of stirrer is capable to distribute the reinforced phase which creates homogeneous dispersion of incorporated phase into the polymer matrix. Consequently, the processing techniques affect the dispersion of nanofiller for any matrixes. Because of this issue, the numerous physical stirring methods such as mechanical stirring, high shear mixing, solvent mixing, and ultrasonic bath stirring were attempted. These methods have been explored to obtain a homogeneous dispersion of nanofiller in the matrix. The results showed that stirring methods had a significant effect on dispersion quality, as the inclusion of voids between nanofiller and matrix reduces the mechanical properties of polymer nanocomposite [37-38]. The appropriate dispersion of reinforcing material into the polymer matrix is also impressed by the pouring rate, pouring temperature and gating systems. The dispersion of reinforcement material is affected during various stages along with (a) dispersion in the matrix as a result of mixing, (b) dispersion in the matrix after mixing, but before curing and (c) redistribution as a result of curing. Some parameters such as relative density, wetting condition of material and settling velocity also affect the distribution of dispersed phase.

\subsection{Ultrasonic Oscillations}

Among various mechanical stirring methods, the ultrasonic vibrations were found more impressive in improving the homogeneous distribution of nanofillers both in solution and melt polymers as compared to other methods. Ultrasonic vibration supply ultrasound waves of higher energy which are capable to break $\mathrm{C}-\mathrm{C}$ bonds resulting in the generation of a large 
number of radicals that form chemical bonds on the clay surface of nanocomposite and interrupt physical and chemical interactions [51]. Therefore this technique has been extensively reported for crushing, emulsifying and dispersing the particles. Xia H.S. et al [52] carried out the ultrasonication method to diminish the agglomeration of nano-silica particles. In 2016, Pattanaika A. [53] examined the epoxy/fly ash composite by using Ultrasonic Technique.

\section{LIMITATIONS AND PROCESS OF IMPROVEMENTS}

Due to improper and insufficient dispersion of nanoparticles, the processing of nanocomposites is one of a major challenge. The nanoparticles exhibit extremely higher surface area and volume effect which causes agglomeration. The improvement in various properties of nanocomposite is strongly associated with the microstructure of nanocomposite.

\section{CHARACTERIZATION OF POLYMER NANOCOMPOSITES}

To install the structure-property relationships for nanocomposite, the characterization of morphology is important. Various techniques such as Scanning electron microscopy (SEM), Transmission electron microscopy (TEM), Infrared spectroscopy (IR) or Atomic force microscopy (AFM) have been reported for characterization of the surface of nanocomposites. Bhuiyan M.A. et al. [54-55] carried out Atomic force microscopy (AFM) to evaluating the morphological variations of the areas around the particle surface. Among these techniques, TEM is the most appropriate method to analyze the state of dispersion of nanoparticles, filler size, local crystallinity, size and shape of void. The only drawback of TEM is that only a small area of material could be analyzed. Wetzel B. [56] carried out the TEM technique to investigate the scattering aspect of nanoparticles. They revealed the homogeneous dispersion of nanoparticles with few cramped aggregates in the polymer matrix. Further, the SEM technique has been carried out for analysis of the cross-sectional area as well as the dispersibility of nanofiller in the matrix. In the SEM technique, a beam of electrons is carried out, which scans the sample and generates images of the samples at various magnifications. $\mathrm{X}$-ray diffraction (XRD) is also an appropriate technique to analyze the space between clay layers. The thermal stability of nanocomposite can be examined by TGA (thermal gravimetric analyzer).

\section{EFFECT OF FLY ASH AND NANOFILLERS ON MECHANICAL, MORPHOLOGICAL, AND THERMAL PROPERTIES OF FLY ASH/EPOXY NANOCOMPOSITES}

In the literature survey, the enhancement in mechanical properties such as Tensile strength, Yield strength, Compressive strength, Hardness, resistance, wear-resistance, and thermal properties are taken into consideration for study the effect of reinforcement of fly ash and nanofiller with different wt $\%$ into the polymer matrix. The mechanical, optical, rheological, flame retardancy and dielectric properties of polymer nanocomposites have been extensively studied. Various authors have revealed some interesting studies on epoxy-based nanocomposites with the incorporation of fly ash and various nanofillers.

In 1988, Srivastava V.K. et al. [57] studied that fly-ash powder is an industrial waste that helps to capture the crack path, thus enhance the mechanical properties of fiber-reinforced plastic (FRP) composites. The ultrasonic technique was performed to determined qualities like toughness, fracture surface energy of epoxy/fly ash, epoxy/carbon fiber/fly-ash, epoxy/glass fiber, and epoxy/glass fiber/fly ash composites. They further studied that properties like fracture toughness and surface fracture energy of continuously coated, uncoated fly-ash filled unidirectional glass fiber reinforced epoxy resin can be enhanced by a 
continuous coating of fiber tows with the epoxy resin before slashing into molding pellet[58]. Ibraheem S. et al. [59] investigated to utilize fly ash, an industrial by-product into developing significant green composite. Fly ash is a waste product can be recycled into low-cost effectiveness and better quality composite as a potential lightweight structure material instead of dumping into the large area of landfills. Different types of fillers like carbon nanotubes, fly ash and milled carbon fiber with different wt $\%$ were reinforced into the matrix to evaluate the mechanical, chemical and morphological properties of composites. They revealed that the reinforcement of CNT nanofillers having a high surface area of bonding enhances the mechanical properties of composites. The effect of epoxy resin to filler proportion on physical and mechanical characteristics of epoxy resin hybrid composites incorporated with fly ash and sawdust were determined by Krishna M.P. et al. [60]. The density and compressive behavior of composites were also explored. The results indicated that the increment in the filler quantity lowered the cost of the composite along with enhanced its durability. Barpanda P. et al. [61] compared the sliding wear behavior of neat epoxy with the epoxy-containing different volume fraction of fly ash. Obtain results showed the different magnitudes of wear loss for neat epoxy and epoxy/fly ash composite. RamaKrishna H.V. et al. [62] studied the utilization of fly ash as reinforcement material in the epoxy/PBT blend matrix. The mechanical properties of PBT (2\%)/epoxy blend matrices such as tensile, impact, flexural compression, chemical resistance, and water absorption properties were found better as approached to epoxy/fly ash composite.

The size of fly ash as a filler also affects the mechanical properties of a composite. Raja R.S. et al. [63] prepared the fly ash/epoxy composite with reinforcement of $10 \mathrm{wt} \%$ of different particle sizes of fly ash $(50 \mu \mathrm{m}, 480 \mathrm{~nm}, 350 \mathrm{~nm}$, and $300 \mathrm{~nm})$ and studied the impact strength and hardness of the composite. The ball milling technique analyzed the reduction in size. The characterization of fly ash was carried out with a Scanning electron microscope (SEM) and energy dispersive spectroscopy (EDS). The strength was found improved with size reduction of fly ash particle.

In 2002, Kishore S.M. [64] evaluated the impact factor of the epoxy/fly ash system. The larger size of particles of fly ash serves as crack initiating points which deteriorate the impact strength of the material. SEM technique demonstrated that fly ash particles affect the crack at all stages. They further [65] studied the mechanical characteristics such as impact, flexural strengths, and flexural modulus of Fly ash Cenospheres/epoxy composite. The impact and flexural modulus of the epoxy composite was found enhanced with increasing the wt $\%$ of FAC's and reached the highest values at $15 \mathrm{wt} \%$ of FAC. Epoxy resin is a thick viscous liquid, so manually mixing of fly ash is quite difficult. So mechanical stirring followed by ultrasonicator was reported. Liu S. et al. [66] studied an epoxy-based carbon nanomaterial's nanocomposite. Verma D. et al. [67] studied the reinforcement of industrial pollutants, fly ash and synthetic fibers like E-glass in different ratio into epoxy resin. The mechanical properties of polymer composite like tensile, flexural and compressive strength were studied. The results revealed that compressive strength, tensile strength, and flexural strength were enhanced by $231.97 \mathrm{MPa}, 48 \mathrm{MPa}$, and $114 \mathrm{MPa}$ with the incorporation of $5 \mathrm{wt} \%$ fly ash. SEM technique was analyzed to check the particle size of fly ash and uniform distribution of fly ash and Eglass fiber into epoxy resin.

Ozsoy I. et al. [68] investigated and compared the tribological and mechanical performance of nano and micro epoxy composite nanofillers such as $\mathrm{Al}_{2} \mathrm{O}_{3}, \mathrm{TiO}_{2}$ and clay and micro fillers like $\mathrm{Al}_{2} \mathrm{O}_{3}, \mathrm{TiO}_{2}$ and fly ash. On pin-on-disc arrangement, wear test was examined under dry atmospheric conditions values $5,10,15 \mathrm{~N}$, Sliding speed $0.8 \mathrm{~m} / \mathrm{s}$ and sliding distance by $2000 \mathrm{~m}$. They concluded that the tribological and mechanical performance of micro filler epoxy composite was found better than nanofiller epoxy composite. Ultrasonic 
synthesis technique help in the formation of long term stable polymerization which consists of polymer/inorganic nanoparticle composite. In the literature survey, it was revealed that the mostly mechanical properties dramatically reduce with further excessive addition of fly ash and nanofillers. Because fly ash particles are a type of rigid particle help to deliver a part of the load to assure the epoxy matrix form. But the excessive addition of fly ash creates agglomeration of fly ash as stress concentration points which posses' physical defects, resulting in damage from these points. Mishra A. [69] investigated the mechanical properties and water absorption capacity of fly ash/epoxy/coconut shell dust (CSP). Tensile strength was enhanced by $15 \%$ by an increment of CSP although dramatically reduced with $20 \mathrm{wt} \%$ of CSP. Recently, Chen P. et al. [70] studied the mechanical properties like impact strength, flexural strength and flexural modulus of Fly ash Cenospheres/EP composites. Fly ash Cenosheres (FAC) is an industrial waste was utilized as a filler to enhance the properties of the epoxy matrix. With the incorporation of increasing weight fraction of FAC with epoxy matrix, the mechanical properties were found better. Higher values were obtained when the weight fraction of FAC's exceeding to $15 \mathrm{wt} \%$. However the further increment in FAC content reduced the mechanical properties of FACs/EP composites.

Chaowasakoo T. et al. [71] have determined or evaluated the effect of conventional thermal and microwave curing methods on the morphological and mechanical properties of fly ash/epoxy composite. The conventional thermal curing was achieved at $70^{\circ} \mathrm{C}$ for $80 \mathrm{~min}$. while the microwave curing was performed at $240 \mathrm{~W}$ for $18 \mathrm{~min}$ to attain the optimum cure of the composite. The results reveal that the tensile, flexural moduli of the fly ash/epoxy composite improved with the increase in the fly ash content while the mechanical strength (tensile, flexural and impact strength) continuously reduced with an increase in fly ash content. The enhancement in mechanical properties could be achieved with the addition of 0.5 wt. \% coupling agent. Prabu V.A. et al. [72] studied for utilization of industrial pollutant such as sawdust, rice husk, fly ash and red mud as reinforcing material such as epoxy and polyester for developing high-performance composite. The fillers were incorporated in different wt $\%$ of $2,4,6,8,10,20,30,40$, and 50. Hand-layup technique was performed for the fabrication of composites and tensile strength, impact strength and hardness were studied. The tensile strength of sawdust and rice husk reinforced composites was enhanced by 14 and $18 \%$ and impact strength by 61 and 142\%. SEM technique was analyzed to study the failure mechanism of composites. The tensile and impact strength of fly ash/epoxy composite was improved by $63 \%$ and $42 \%$ due to the good mechanical performance of fly ash in a polyester matrix. Baheti V. et al. [73] prepared the fly ash/epoxy composite by ball milling technique. Three-layered laminated composite of glass fabrics was prepared with reinforcement of nanofiller into the epoxy matrix. The obtained results indicate that with the incorporation of activated fly ash with different weight $1,3,5$ and $10 \mathrm{wt} \%$ at $200^{\circ} \mathrm{C}$, the storage modulus of the nanocomposite was improved by $85.71,38.09,104.76$ and $80.95 \%$ as compared to neat composites.

\section{APPLICATIONS OF EPOXY/ FLY ASH NANOCOMPOSITES}

The epoxy/fly ash nanocomposite is a multiphase system with excellent properties and ecofriendly. Therefore, the applications of nanocomposite propose new opportunities for several sectors of aerospace, automotive and electronics applications. However, no single application establish $100 \%$ utilization of fly ash thus a large number of skillful application is needed for assisting and bettering the utilization of fly ash. The innovative applications of fly ash offer opportunities to further enhance the utilization. 


\section{RESEARCH GAP WHERE THE WORK IS AIMED}

The literature review was revealed that work on composite based on fly ash, epoxy resin and nanofiller has hardly done in the past. In the literature survey, it has also reported that the mostly mechanical properties dramatically reduce with further excessive addition of fly ash and nanofillers. Therefore, for a particular application, the optimum level should be analyzed. So, an idea of developing high-performance composite matrices by utilization of waste material fly ash, nanofiller, and epoxy resin has emerged into mind based on literature survey. A lot of efforts have been required to utilize the industrial waste fly ash. With the incorporation of inorganic and nanoparticles, nucleation of crystallization can appear. The nucleation of crystallization developed with the reinforcement of inorganic and nanoparticles. Therefore at the nanoscale, the nanoparticle can change for deficiency of primary nuclei emulating with trapped crystallization. At higher content of nanofiller, lower crystallization kinetics is achieved due to higher viscosity. At low concentrations, the nucleation of crystallization was monitored by the Onset temperature of crystallization (Tc) and crystallization half-time. Slightly an interruption in the rate of crystallization has been observed at higher concentrations. This was alike observed in specific composites, where nucleation viewed at low concentrations [74-80].

\section{CONCLUSION}

In this context, nanocomposites are suitable materials to meet the emerging demands arising from scientific and technologic advances. They are generally more advantageous composites because the enhancement in properties of nanocomposite can be acquired from the addition of the small amount of nano-sized filler content having a high aspect ratio. The review article covers the effect of nanoparticles on mechanical characteristics including impact strength, flexural strength and tensile strength of fly ash/epoxy composite and fly ash/epoxy nanocomposites. It has concluded that the reinforcement of nanofiller even in small content enhances the mechanical properties of fly ash/epoxy composite. Because the homogeneous dispersion of nanofillers reduced the defects between fillers and polymer interface, resulting in improvement in the mechanical properties of filler/fly ash/epoxy nanocomposites. Finally, the review core provides a few awareness of safety and predictability features that would impact the market comeback for new nanocomposites. The increment in the progressive rate of utilization of fly ash also depends upon the government directives. The utilization of fly ash will sustain the natural raw material and diminished the disposal cost. While keeping safe the environment, fly ash will also bring out the business opportunities at the same time. To develop the epoxy nanocomposites with enhanced mechanical properties is associated with (a) The modification of nanofillers with functionalities to enhance the dispersion quality of the nanofillers (b) To improve the interfacial interaction between the nanofillers and the polymer matrix is mandatorily required. Hence, to explore the new functionalities of filler/fly ash/epoxy nanocomposites is the main effort for researchers in the future.

\section{ACKNOWLEDGEMENT}

I express to my sincere thanks to Prof. Deepak Srivastava, Head of Plastics Technology for providing me the guidance and facilities. 


\section{REFERENCES}

[1] Senapati, M.R. Fly ash from thermal power plants-waste management's and overview. Current Science. (2011). v.100, p.1791-1794. https://www.jstor.org/stable/24077549

[2] Singh, S., Pillai, A. (March 5, 2019). A Compressive Review on Fly Ash Characteristics and Current Utilization Status in India. Proceedings 2019: Conference on Technologies for Future Cities (CTFC).http://dx.doi.org/10.2139/ssrn.3347052.

[3] Haque, ME. Indian fly-ash: production and consumption scenario. International Journal of Waste Resources (IJWR). (2013). v. 3, p. 22-25. DOI: 10.12777/ijwr.3.1.2013.22-25

[4] Flues, M., Sato, I.M., Scapin, M.A., Cotrim, M.E.B., Camargo, I.M.C. Toxic elements mobility in coal and ashes of Figueira coal power plant. Brazil, Fuel. (2013). v. 103, p. 430-436. https://doi.org/10.1016/j.fuel.2012.09.045.

[5] Fernandez-Turiel, J.L., Carvalho, W.de, Cabanas, M., Querol, X., Lopez-Soler A. A Mobility of Heavy Metals from Coal Fly ash. Journal of Environmental Geology. (1994). v. 23, p. 264-70.DOIhttps:// doi.org/10.1007/BF00766741.

[6] Margallo, M., Cobo S., Laso, J., Fernández, A., Muñoz, E., Santos, E., Aldaco, R., Irabien, A. Environmental performance of alternatives to treat fly ash from a waste to energy plant. Journal of Cleaner Production. (2019). v. 231, p. 1016-1026. https://doi.org/10.1016/j.jclepro.2019.05.279.

[7] Fulekar, M.H., Dev, J.M. Disposal of the fly ash-an environmental problem. International Journal of Environmental Studies. (1986). v. 26, p. 191-215. https://doi.org/10.1080/00207238608710257.

[8] Anandhan, S. Recent Trends in Fly Ash Utilization in Polymer Composites. International Journal of Waste Resources. (2014) v. 4. DOI: 10.4172/2252-5211.1000149.

[9] Srivastava, I., Koratkar, N., Fatigue and fracture toughness of epoxy nanocomposites. JOM. (2010). 62, p. 50-57. DOIhttps://doi.org/10.1007/s11837-010-0032-8.

[10] He, H., Li, K., Wang, J., Sun, G., Li, Y., Wang, J. Study on thermal and mechanical properties of nano-calcium carbonate/epoxy composite. Materials and Design. (2011) v. 32, p. 4521-4527. https://doi.org/10.1016/j.matdes.2011.03.026.

[11] Hosokawa, M., Naito, M., Nogi, K., Yokoyama, T. Nanoparticle Technology Handbook, Elsevier, Oxford, UnitedKingdom Chap. 1. (2008).

[12] Borisenko, Victor, E., Ossicini, Stefano.A Handbook on Nanoscience and Nanotechnology, Wiley-VCH Verlag GmbH, Weinheim German. 2004wiwn.book. B. (2004).

[13] Camargo, P.H.C., Satyanarayana, K.G., Wypych, F. Nanocomposites: Synthesis, Structure, Properties and New Application Opportunities. Materials Research. (2009) v. 12, p. 1-39. http://dx.doi.org/10.1590/S1516-14392009000100002.

[14] Page, A.L., Elseewi, A.A., Straughan, I.R. Physical and chemical properties of flyash from coal-fired power plants with reference to environmental impacts. Residue Rev. (1979) v. 71, p. 83-120. DOIhttps://doi.org/10.1007/978-1-4612-6185-8_2.

[15] Ibraheem, S., Bandyopadhyay, S. A review of the structure-property research on hybridreinforced polymer composites. Hybrid Polymer Composite Materials. (2017) p.163-191. https://doi.org/10.1016/B978-0-08-100791-4.00007-0.

[16] Ahmaruzzaman, M., A review on the utilization of fly ash. Prog Energy Combust Sci. (2010) v. 36, p. 327-363. https://doi.org/10.1016/j.pecs.2009.11.003.

[17] Carlson, C.L. Adriano, D.C. Environmental Impacts of Coal Combustion Residues. Journal of Environmental Quality. (1993) v. 22, p. 227-247. doi:10.2134/jeq1993.00472425002200020002x.

[18] Lokeshappa, B., Dikshit, A.K. Disposal and Management of Fly ash International Conference on Life Science and Technology IPCBEE IACSIT Press, Singapore. (2011). 
[19] Satapathy, S., Nando, G.B., Nag, A., Raju, K.V.S.N. HDPE-Fly Ash/Nano Fly Ash Composites, J App Polym Sci. (2013) v.130, p. 4558-4567. https://doi.org/10.1002/app.39733.

[20] Nath, S., Jena, H., Priyanka, Sahini, D. Analysis of Mechanical Properties of Jute Epoxy Composite with Cenosphere Filler. Silicon. (2019) v.11, p. 659-671. DOIhttps://doi.org/10.1007/s12633018-9941-x.

[21] Naik, T.R., Singh, S.S. Fly Ash Generation and Utilization - An Overview, For publication in the book titled Recent Trend in Fly Ash Utilization. (1993)

[22] Yadav, V.K., Fulekar, M.H. The current scenario of thermal power plants and fly ash: production and utilization with a focus in India. International Journal of Advance Engineering and Research Development. (2018) v. 5, p. 768-777.

[23] Manz, O.E. Worldwide Production of Coal Ash and Utilization in Concrete and Other Products, Proceedings of the Tenth International Ash Use Symposium, ACAA, Orlando, Florida. (1993) v. 64, p. 1-12.

[24] Manz, O.E., Faber JH., Takagi H. Worldwide Production of Fly Ash and Utilization in Concrete, Proceedings of the Third International Conference on the Use of Fly Ash, Silica Fume, Slag and Natural Pozzolans in Concrete. (1989) p. 1-15.

[25] Senapati, A.K., Bhatta, A., Mohanty, S., Mishra, P.C., Routra, B.C.: An Extensive Literature Review on the Usage of Fly Ash as a Reinforcing Agent for Different Matrices. International Journal of Innovative Science and Modern Engineering (IJISME) (2014) 2, p. 4-9. ISSN:2319-6386.

[26] Singla, M., Chawla, V. Mechanical Properties of Epoxy Resin - Fly Ash Composite. Journal of Minerals \& Materials Characterization \& Engineering. (2010) v. 9, p. 199-210. DOI:10.4236/jmmce.2010.93017.

[27] Gu, H., Ma, C., Gu, J., Guo, J., Yan, X., Huang, J., Zhang, Q., Guo, Z. An overview of multifunctional epoxy nanocomposites .Journal of Materials Chemistry C. (2016) v. 4, p. 5890-5906.DOI:10.1039/C6TC01210H.

[28] Mohanty, N.R., Nayak, S.K.: Synthesis and Modifications of Epoxy Resins and Their Composites: A Review. Polymer-Plastics Technology and Engineering. (2014) v. 53, p. 1723-1758.https://doi.org/10.1080/03602559.2014.919658.

[29] Azeez A.A., Rhee K.Y., Parkb S.J., Huiac D. Epoxy clay nanocomposites- processing, properties, and applications: A review. Composites Part B: Engineering. (2012) v. 45, p. 308-320.https://doi.org/10.1016/j.compositesb.2012.04.012.

[30] Wittman, C., Shook, G.D.: Hand Lay-Up Techniques. Handbook of Composites. 321-367.

[31] Purohit, R., Sahu, P., Rana, R.S., Parashar, V., Sharma, S. Analysis of Mechanical Properties of Fiber Glass-Epoxy-Fly Ash Composites. materials today Proceeding. (2017) v. 4, p. 3102-3109.https://doi.org/10.1016/j.matpr.2017.02.193.

[32] Niroumand, Synthesis and characterization of 356-SiCp composites by stir casting and compocasting methods. Trans. Nonferrous Met.Soc.China. (2010) v. 20, p. 788-793. https://doi.org/10.1016/S1003-6326 (10)60582-1.

[33] Mahapatra, M.M.: Fabrication and Characterizations of Mechanical Properties of Al4.5\% Cu/10TiC Composite by In-Situ Method. Journal of Minerals and Materials Characterization and Engineering. (2012), p. 1075- 1080. https://doi.org/10.1155/2017/9314740.

[34] International Organization for Standardization (ISO). Nanotechnologies-Vocabulary. In Part 2: Nano-Objects; International Organization for Standardization: Geneva, Switzerland 2015.

[35] Hosokawa, M., Naito, M., Nogi, K., Yokoyama, T. (2007) Nanoparticle Technology Handbook; Elsevier Science: Oxford, UK. 
[36] Bugnicourt, E. Development of Sub-Micro Structured Composites based on an Epoxy Matrix and Pyrogenic Silica: Mechanical Behavior Related to the Interactions and Morphology at Multi-Scale. Ph.D. Thesis, Intelligence and National Security Alliance (INSA), Villeurbanne, France 2005.

[37] Bhushan, B. (2010). Springer Handbook of Nanotechnology, 3rd ed.; Springer: Berlin, Germany.

[38] Hosokawa, M., Naito, M., Nogi, K., Yokoyama, T.: (2008). Nanoparticle Technology Handbook, Elsevier, Oxford, UnitedKingdom Chap. 1.

[39] Tomi M.D., Dunji B., Likić V., Bajat J., Rogan J., Djonlagić J. The use of nanoclay in preparation of epoxy anticorrosive coatings. Prog. Organ. Coat. (2014) v. 77, p. 518-527. https://doi.org/10.1016/j.porgcoat.2013.11.017.

[40] Zolotuchin, I. Carbon Nanotubes, Soros Educational Journal: Voronezh State University. (1999) v. 3, p. 111-115.

[41] Holister, P., Harper, T., Vas, C.R.: Nanotubes. White Paper. [e-journal] Las Rozas: CMP Científica. (2003), Accessed 10 March 2012.

[42] Yue, L., Pircheraghi, G., Monemian, S.A., Manas-Zloczowe, I. Epoxy composites with carbon nanotubes and graphene nanoplatelets-Dispersion and synergy effects. Carbon. (2014) v. 78, p. 268-278.https://doi.org/10.1016/j.carbon.2014.07.003.

[43] Rasheed, A., Khalid, F.A. Fabrication and properties of CNTs reinforced polymeric matrix nanocomposites for sports applications. IOP Conf. Ser. Mater. Sci.Eng. (2014) DOI:10.1088/1757-899X/60/1/012009.

[44] Suh, D.J., Lim, Y.T., Park, O.O. The properties and formation mechanism of unsaturated polyester-layered silicate nanocomposite depending on the fabrication methods. Polymer. (2000) v. 41, p. 8557-8563. https://doi.org/10.1016/S0032-3861 (00)00216-0.

[45] Carrado, K.A., Xu, L.Q. In situ synthesis of polymer-clay nanocomposites from silicate gels. Chem. Mater. (1998) v. 10, p. 1440-1445. DOI: 10.1021/cm970814n.

[46] [46]. Messersmith, P.B., Giannelis, E.P. Synthesis, and characterization of layered silicate-epoxy nanocomposites. Chem. Mater. (1994) v. 6, p. 1719-1725. https://doi.org/10.1021/cm00046a026

[47] Vaia, R.A., Giannelis E.P. Polymer melt intercalation in organically-modified layered silicates: Model predictions and experiment. Macromolecules. (1997) v. 30, p. 8000-8009. https://doi.org/10.1021/ma9603488.

[48] Vaia, R.A., Giannelis E.P. Lattice model of polymer melt intercalation in organically modified layered silicates. Macromolecules. (1997) v. 30, p. 7990-7999. DOI: 10.1021/ma9514333.

[49] Jiankun, L., Yucai, K., Zongneng, Q., Xiao- Su, Y. Study on intercalation and exfoliation behavior of organoclays in epoxy resin. Journal of Polymer Science: Part:B. (2001) v. 39, p. 115-120. https://doi.org/10.1002/1099-0488 (20010101)39:1<115: AIDPOLB100>3.0.CO;2-N .

[50] Tomic, M., Dunjic, B., Nikolic, M.S., Maletaškic, J., Pavlovic, V.B., Bajat, J., Djonlagic, J. Dispersion efficiency of montmorillonites in epoxy nanocomposites using solution intercalation and direct mixing methods. Applied Clay Science. (2018) v. 154, p. 52-63. https://doi.org/10.1016/j.clay.2017.12.047.

[51] CK., Lam, KT., Lau, Cheung, Ling, HY. Effect of ultrasound sonication in nanoclay clusters of nanoclay/epoxy composites. Materials Letters. (2005) v. 59, p. 1369-1372. https://doi.org/10.1016/j.matlet.2004.12.048.

[52] Xia, H., Wang, Q.: Preparation of conductive polyaniline/nanosilica particle composites through ultrasonic irradiation. J. Appl. Polym. Sci. (2003) v. 87, p. 1811-1817. https://doi.org/10.1002/app.11627. 
[53] Pattanaika, A., Satpathy, M.P., Mishra, S.C. Dry sliding wear behavior of epoxy fly ash composite. Taguchi optimization Engineering Science and Technology, an International Journal. (2016) 19, p. 710-716. https://doi.org/10.1016/j.jestch.2015.11.010.

[54] Bhuiyan, M.A., Pucha, R.V., Karevan, M., Kalaitzidou, K.: Tensile modulus of carbon nanotube/polypropylene composites - A computational study based on experimental characterization. Comput. Mater. Sci. (2011) 50, p. 2347-2353. DOI:10.1016/j.commatsci.2011.03.009.

[55] Bhuiyan, M.A., Pucha, R.V., Karevan, M., Kalaitzidou, K., Worthy, J. Defining the lower and upper limit of the effective modulus of CNT/polypropylene composites through integration of modeling and experiments. Compos. Struct. (2013) v. 95, p. 80-87. DOI: 10.1016/j.compstruct.2012.06.025.

[56] Wetzel, B., Rosso, P., Haupert, F., Friedrich, K. Epoxy nanocomposites-fracture and toughening mechanisms. Engineering Fracture Mechanics. (2006) v. 73, p. 2375-98. DOI10.1016/j.engfracmech.2006.0

[57] Srivastava, V.K., Shembekar, P.S., Prakash, R. Fracture behavior of fly-ash filled FRP composites. Composite Structures. (1988) v.10, p. 271-279. https://doi.org/10.1016/02638223(88)90006-2.

[58] Srivastava, V.K.: Effect of fibres coating on fracture properties of composite. Engineering Fracture Mechanics. (1989) v. 34, p. 777-782. https://doi.org/10.1016/0013-7944 (89)90138-0.

[59] Ibraheem, S., Devasahayam, S., Standard, O., Bandyopadhyay, S.: Use of Secondary Ion Mass Spectrometry (SIMS) to identify fly ash mineral spatial and particulate distribution in epoxy polymer. International Journal of Mineral Processing. (2015) v. 142, p. 139-146. https://doi.org/10.1016/j.minpro.2015.04.025.

[60] Krishna, M.P., Kireeti, M.P., Krishna, M.R., Jyothi, Y., Swami, G.R.K. Mechanical properties of fly ash/sawdust reinforced epoxy hybrid composites. Journal home page for Materials Today: Proceedings. (2018) v. 5, p. 13025-13030. https://doi.org/10.1016/j.matpr.2018.02.288.

[61] Barpanda, P., Kulkarni, S.M., Kishore. Sliding Behavior of an Epoxy System Reinforced with Particulate Fly Ash Filler, Advanced Composites Letters. (2009).

[62] Ramakrishna, H.V., PadmaPriya, S., Rai, S.K.: Utilization of fly ash as filler for polybutyleneterethalate-toughened epoxy resin. (2006), https://doi.org/10.1002/pen.20557.

[63] Raja, R.S., Manisekar, K., Manikandan, V. Effect of fly ash filler size on mechanical properties of polymer matrix composites. International Journal of Mining, Metallurgy \& Mechanical Engineering (IJMMME). (2013), 1(1) ISSN 2320-4060.

[64] Kishore, Kulkarni S.M., Sharathchandra S., Sunil D. On the use of an instrumented set-up to characterize the impact behavior of an epoxy system containing varying fly ash content. Polymer Testing. (2002) v. 21, p. 763-771.

[65] Kulkarni, S.M., Kishore. Effects of surface treatments and size of fly ash particles on the compressive properties of epoxy-based particulate composites. Journal of Material Science. (2002) v. 37, p. 4321-4326. DOIhttps://doi.org/10.1023/A:1020648418233.

[66] Liu, S., Chevali, V.S., Xu, Z., Hui, D., Wang, H. A review of extending performance of epoxy resins using carbon nanomaterials. Composites Part B: Engineering. (2018) v. 136, p. 197-214.https://doi.org/10.1016/j.compositesb.2017.08.020.

[67] Verma, D., Joshi, G., Dabral, R., Lakhera, A. Processing and evaluation of mechanical properties of epoxy-filled E-glass fiber-fly ash hybrid composites. Woodhead Publishing Series in Composites Science and Engineering. (2019), p. 293-306. https://doi.org/10.1016/B978-0-08102292-4.00015-1. 
[68] Özsoy, I., Mimaroglu, A., Una, H. Comparison of the tribological and mechanical performance for nano and micro filler epoxy composites. Materials Testing. (2016) v.58, p. 376-380.https://doi.org/10.3139/120.110893.

[69] Mishra, A. Mechanical properties of Coconut Shell Dust, Epoxy-Fly Ash Hybrid Composites, AJER. (2017) v. 6, p. 166-174. e-ISSN: 2320-0847 p-ISSN: 2320-0936.

[70] Chen, P., Li, J., Zhang, L. Analysis of mechanical characteristics of fly ash cenospheres reinforced epoxy composites. Journal of the Wuhan University of Technology-Mater. Sci. Ed. (2018) v. 33, p. 139-145. DOI https://.org/10.1007/s11595-018-1798-8.

[71] Chaowasaako, T., Sombatsompop, N. Mechanical and morphological properties of fly ash/epoxy composites using conventional thermal and microwave curing methods. Composites Science and Technology. (2007) v. 67, p. 2282-2291. https://doi.org/10.1016/j.compscitech.2007.01.016.

[72] Prabu, V.A., Johnson, R.D.J., Amuthakkannan, P., Manikandan, V. 2017. Usage of industrial wastes as particulate composite for environment management: Hardness, Tensile and Impact studies. Journal of Environmental Chemical Engineering. (2017), p. 1289-1301. https://doi.org/10.1016/j.jece.2017.02.007.

[73] Baheti, V., Militky, J., Mishra, R., Behera, B.K. Thermomachenicals properties of glass fabric/epoxy composites filled with fly ash. Composite B: Engineering. (2016) v. 85, p. 268-276.https://doi.org/10.1016/j.compositesb.2015.09.049.

[74] Zhang, Q.X., Yu, Z.Z., Yang, M., Ma, J., Mai, Y.W. Multiple melting and crystallization of nylon-66/montmorillonite nanocomposite. J. Polym. Sci. Part B. (2003) v. 41, p. 28612869. DOI:10.1002/polb.10608.

[75] Mu, B., Wang, Q., Wang, H., Jian, L. Nonisothermal crystallization kinetics of nylon 66/montmorillonite nanocomposites. J. Macromol. Sci. Part B. (2007) v. 46, p. $1093-$ 1104.

[76] Nam, J.Y., SinhaRay, S., Okamoto, M. Crystallization behavior and morphology of biodegradable polylactide/layered silicate nanocomposite. Macromolecules. (2003) v. 36, p. 7126-7131. DOI:10.1021/ma034623j.

[77] Lincoln, D.M., Vaia, R.A., Krishnamoorti, R. Isothermal crystallization of nylon6/montmorillonite nanocomposites. Macromolecules. (2004) v. 37, p. 4554-4561. DOI: 10.1021/ma049768k.

[78] Li, L., Li, C.Y., Ni, C., Rong, L., Hsiao, B. Structure and crystallization behavior of nylon 66/multi-walled carbon nanotube nanocomposites at low carbon nanotube contents,

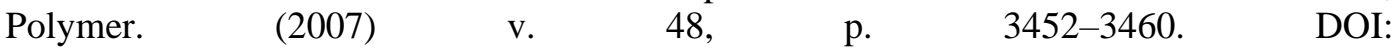
https://doi.org/10.1016/j.polymer.2007.04.030.

[79] Phang, I.Y., Pramoda, K., Liu, T., He, C. Crystallization and melting behavior of polyester/clay nanocomposites. Polym. Int. (2004) v.53, p. 1282-1289. DOI: 10.1002/pi.1513.

[80] Wu, D., Zhou, C., Fan, X., Mao, D., Bian, Z. Morphology, crystalline structure and isothermal crystallization kinetics of polybutylene terephthalate/montmorillonite nanocomposites. Polym. Compos. (2005) v. 13, p. 61-71. 